\section{A BRIEF ACCOUNT OF \\ A METHOD OF PROVIDING BATHS FOR THE SOLDIER IN THE FIELD.}

\author{
BY H. NORMAN Goode, M.B.Lond., \\ F.R.C.S.EDIN., D.P.H., \\ CAPTAIN, R.A.M.C. (T.)
}

Cleanliness, as is well known to those who have been in the trenches, is a matter of the greatest difficulty under the present conditions. Men have to remain in the trenches without any opportunity of washing or changing their clothes. In consequence they get covered with lice, chiefly pediculi vestimentorum. These cause great irritation, and rob them of sleep when off duty. The lice inhabit chiefly the shirt, pants, and trousers, in which millions of eggs are laid in a very short space of time. To alleviate this arrangements are now made throughout the British army for the men to have baths and a change of underclothing as soon as they come out of the trenches. The following is the method adopted by a certain division.

I will first give a description together with a plan of the baths themselves, then the routine of bathing the men, and, lastly, the method I have devised, in conjunction with Captain Basil Hughes, of Bradford, for purifying and using the water over again an indefinite number of times.

\section{Description and Plan of Baths.}

As regards the building itself, a perspective view and ground plan are subjoined. (Figs. 1 and 2.) The canvas structure, with which I originally commenced, has now been replaced by a portable wooden building. This was kindly presented by the West Riding of York County Association through the instrumentality of Lord Scarbrough and General Mends.

From the ground plan it will be seen that it consists of a large undressing-room, a bath-room with eight "showers," the officers' shower bath, a large dressing-room, a room for soiled under-
Fig. 2.

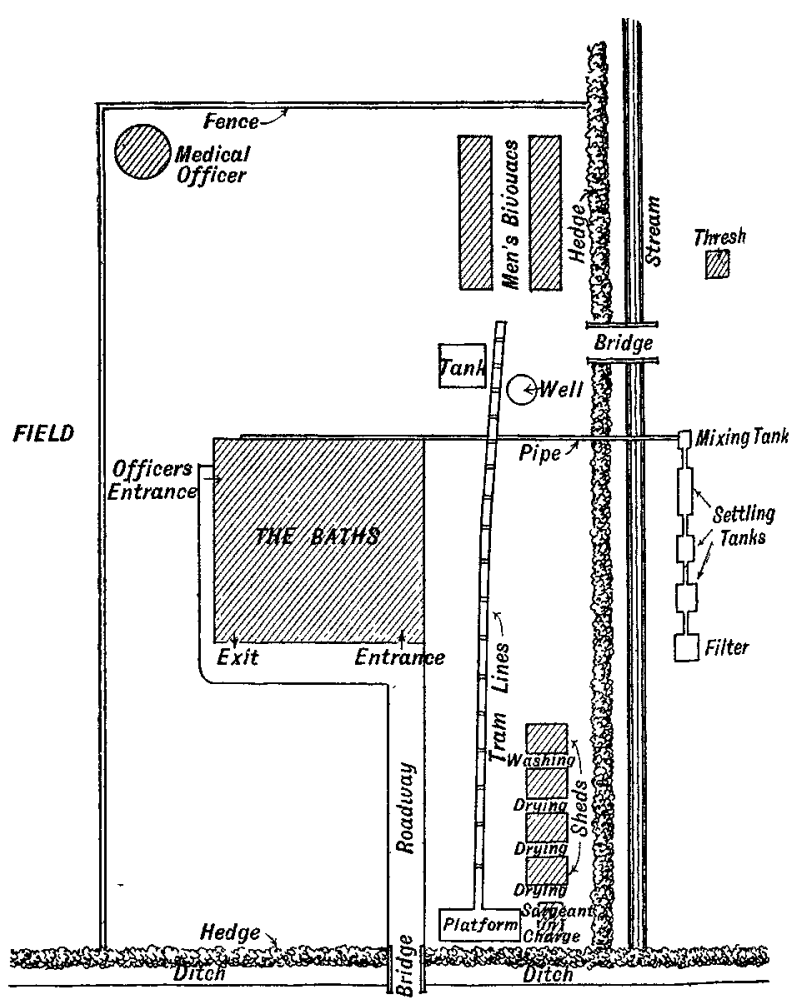

ROAD

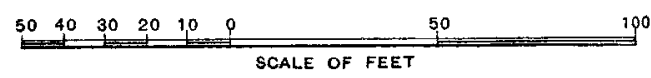

Ground plan of the bathing installation.

clothing, a store-room for the issue of clean clothing, a boiler-room, and an ironing-room for the purpose of destroying the eggs and lice in the khaki clothing. (Fig. 3.)

The water is pumped by means of a little petrol engine into a sixteen-hundred-gallon tank, 24 feet high; thence it runs by gravity to the two connected tanks which feed the boilers, which are independent of one another. The water-hot, cold, or mixed hot and cold-feeds the eight sprays by gravity, sprays being used to economise water.

FIG. 1.

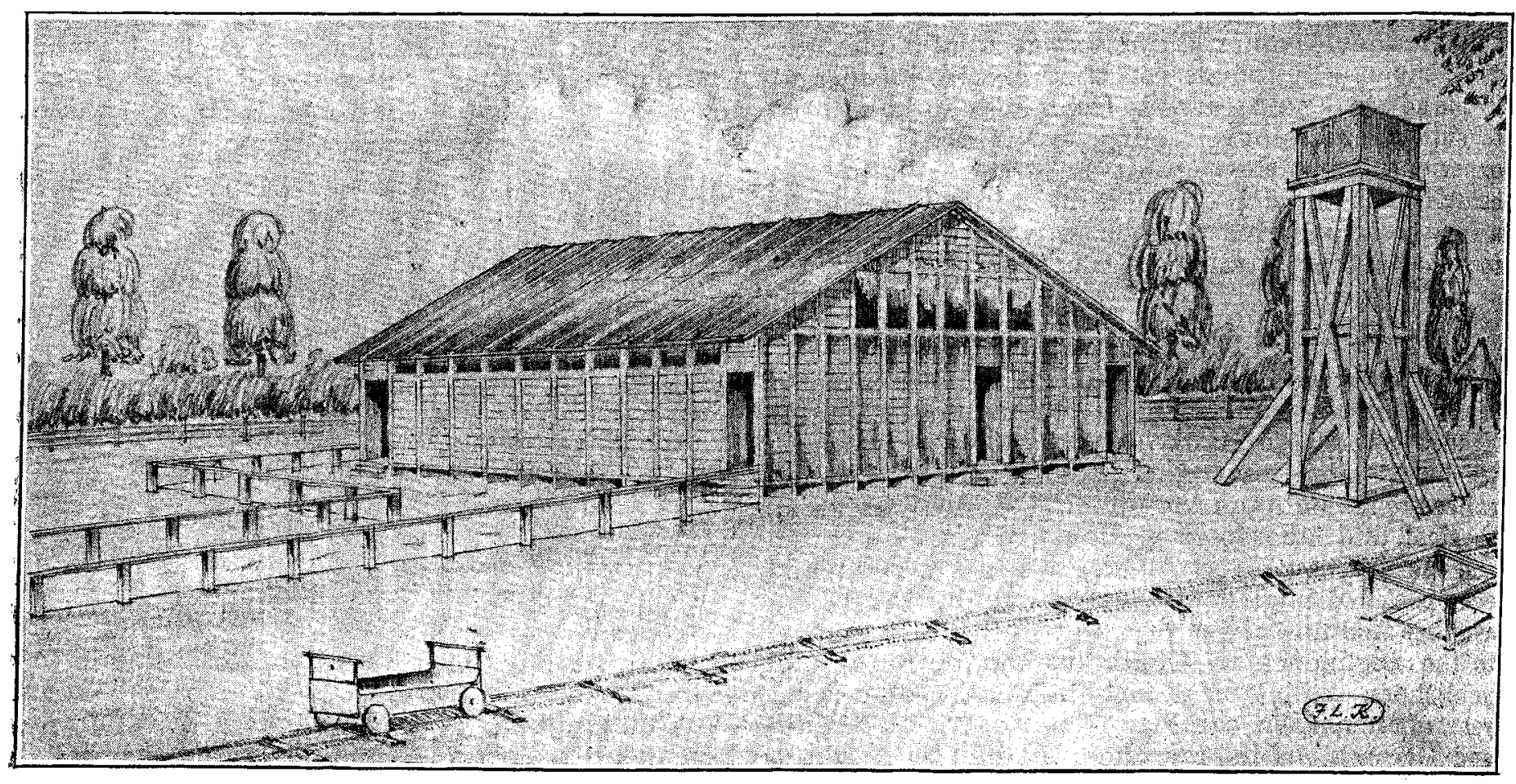


since only one-and-a-half to two gallons are required per man, instead of six when using tubs. (Fig. 4.) Originally every drop of water had to be carried to the baths by means of a motor tank holding 120 gallons from a stream about one-and-a-half miles away, as, for convenience of the troops, the baths had to be placed in a field some way from the nearest brook. Now, however, there are three sources: a shallow well providing about a thousand gallons a day; a storage tank, containing water brought from the stream and rain-water from the roof; and the concrete well. containing the purified used water. The process of purifying the used water I will describe later. These three sources are connected up to the motor pump. Thus any one may be used separately to supply the elevated storage tank.

\section{Method of Bathing.}

The method employed for bathing the men is as follows: Two thousand men can be bathed per diem. The maximum in one day, so far, has been 2050. The men are sent to the baths in batches of from 50 to 75 every half-hour, commencing at 8 A.M. and continuing until 12 noon; then again from 2 P.M. to 6 P.M. The men come to the baths without arms as a rule. Here they undo their puttees and boots and take off their tunics. They then enter the undressing room in batches of 32, and undress. Their breeches are then handed into the ironing room, where they are ironed in order to kill the lice and nits. The trousers are usually put through the Thresh disinfector. The men, in batches of 16 , then pass through to the sprays, handing in to the soiled. clothes room their shirts, socks, and pants. Three minutes is the usual time allowed under the hot sprays, during which time they soap themselves all over, the last half-minute being used to wash off all the soap. In the summer the last half-minute consists of a cold "shower." Thence they go into
FIG. 4.

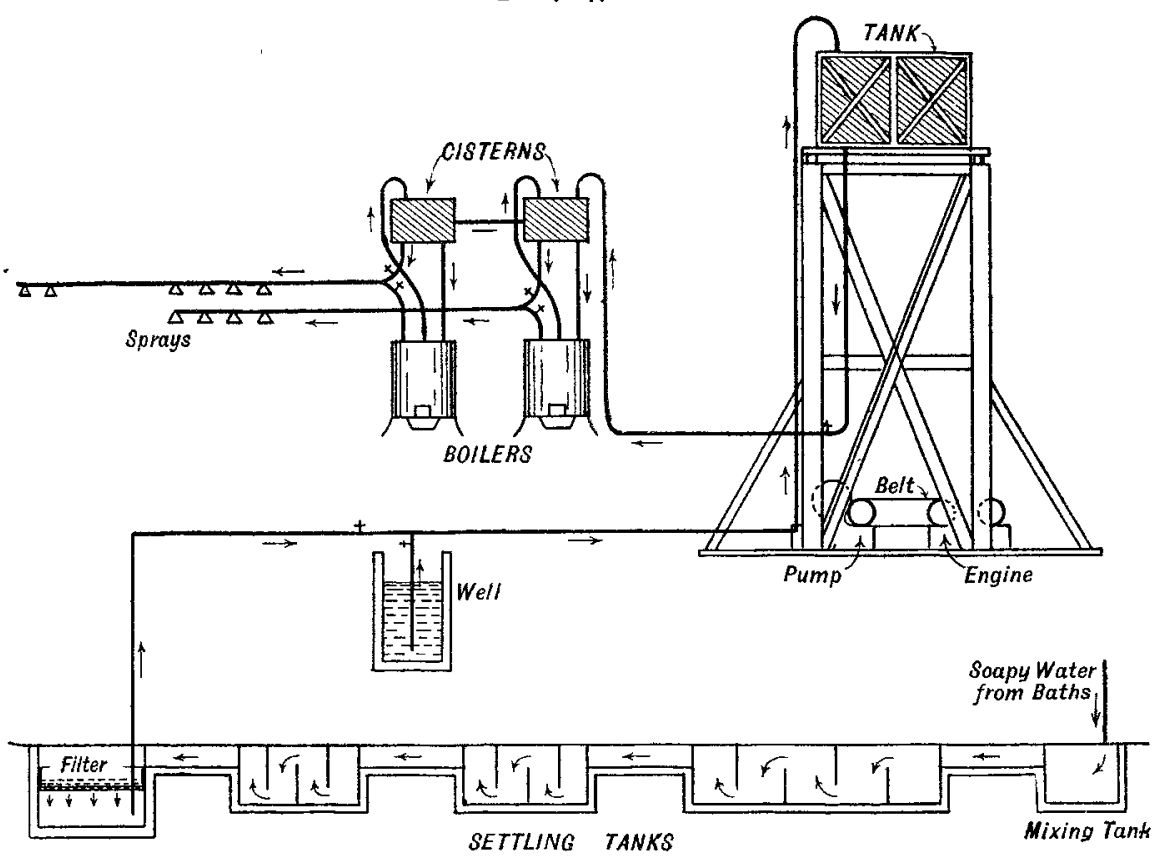

Diagram of the water-supply and filter-beds. they were taken, the numbers being painted on the tables. When dressed they leave by the exit door and form up outside, another batch of 16 imme. diately following through in the same order.

Thus it will be seen that the underclothes are pooled. The shirts and pants are put through the FiG. 3

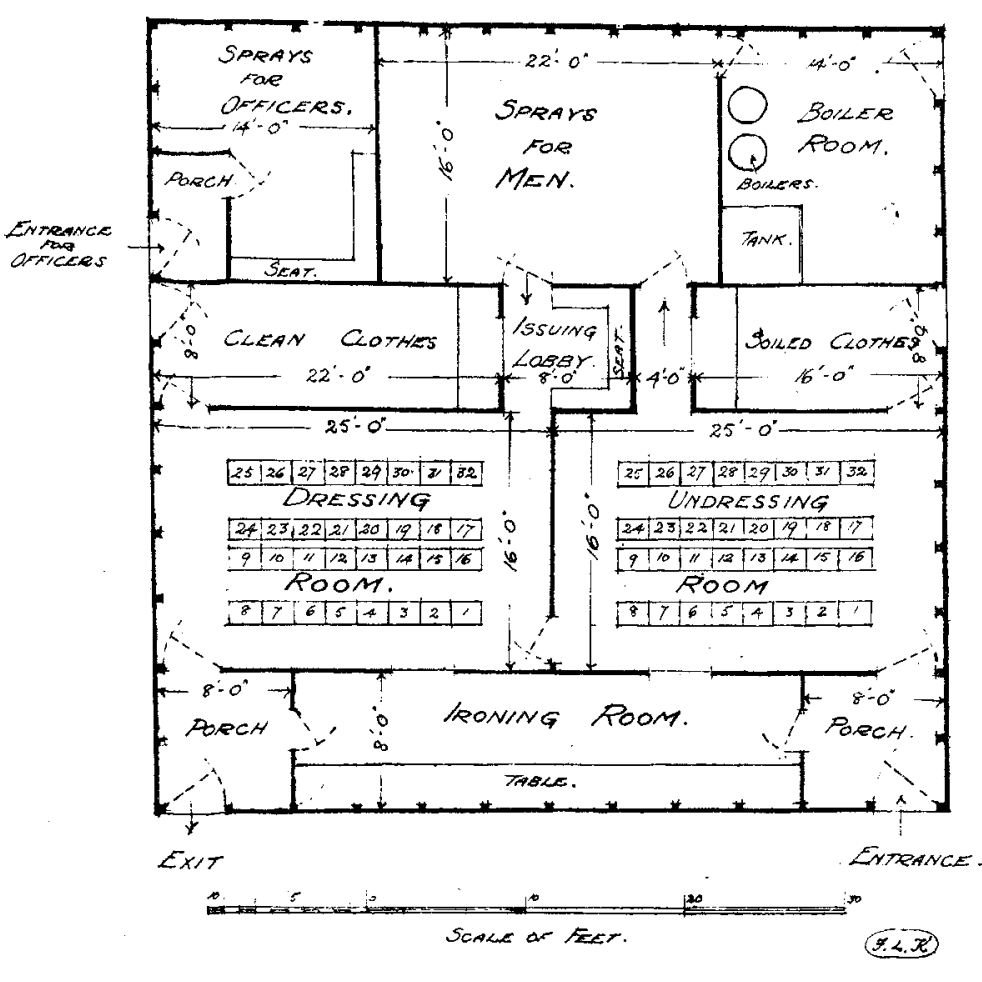

Ground plan of the bath-room.

Thresh disinfector in lots of 80 for 20 to 30 minutes at a temperature of $216^{\circ} \mathrm{F}$. Twenty minutes suffice if a bottle of formalin has been poured into the disinfector. The clothes are sorted and the unserviceable portion is burnt. The following morning the rest of the clothes are conveyed in wagons to a distributing centre in a village eight miles away. This is the nearest available place where spring water abounds and where labour is obtainable away from the firing line. Here a responsible woman sorts and distributes the clothing to 50 washerwomen, who boil, wash, dry, iron, and mend them, and then return them tied up in bundles of 10 to the distributing centre. The sarne wagons, after being washed with cresol solution, return to the baths with loads of clean clothes, each batch of clothes being returned on the third day. Several thousands of new shirts, pants, and socks are required monthly to replace wastage.

\section{Treatment of the Used Water.}

The last point of interest is the method of using the water over again. This is of the highest importance for two reasons: First, clean water, or even water of any kind, is very scarce in this part of Belgium in summer: secondly, it is highly objectionable the dressing room, being served out on the way with to pour from 2000 to 4000 gallons of soapy a clean shirt, a pair of pants, and a pair of socks. Water into the ditch near the baths. If this were Meanwhile an attendant has brought round their allowed it would accumulate and decompose in boots, tunics, and other belongings from the the hot sun, since owing to the flatness of the undressing room to the dressing room, placing them country there are no possible means of draining on a number corresponding with that from which it away. 
The following method was devised by Captain Basil Hughes and myself after a number of experiments with a working model.

From Fig. 4 it will be seen that the soapy water runs from the bath-house into a mixing-tank. Slaked lime is placed in this tank, and thoroughly mixed by means of a windmill-mixer constructed from a couple of old bicycle wheels and a hop pole. When the wind fails the mixing must be done by hand; but this is hard work. The lime throws down the soap as insoluble calcium stearates, bringing down at the same time all the dirt and impurities. The effluent runs through three up-and-down settling-tanks, placed all on the same level. These are built of brick with concrete floors. The partitions are removable wooden frames with canvas centres. The three settling tanks are respectively 3,4 , and 5 feet wide. This gradual widening of the tanks tends to retard the flow of the stream, thereby assisting precipitation. All the calcium stearates will be found to have settled down in the first two tanks. The third tank is used for precipitating the lime and removing the soapy oils. This is effected by means of washing soda, which is run into the tank from a drum containing a saturated solution of sodium carbonate. This precipitates the calcium saltschiefly hydroxides-as insoluble calcium carbonate, which immediately falls to the bottom of the tank. In addition to this the sodium carbonate causes the soluble oils from the soap to separate out. These oils, which give the water an odour of soap, float on the surface, and are absorbed by means of canvas or sacking nailed on to wooden frames. The canvas is changed daily. From this third settling tank the water flows into a charcoal filter containing 4 inches of powdered charcoal between two layers of sacking. Through this filter it runs down into a bricked, concreted well, and is pumped thence into the elevated tank by the petrol pump. Thin canvas screens, stretched on strong wire frames, are placed in the channels connecting the precipitating tanks. These hold back the scum of lime which separates out on the water cooling. The first precipitation tank is cleaned out every three or four days, and the mixing tank daily. The sludge is buried. The sludge, which is odourless except for a slight smell of lime, does not show any tendency to decompose. The water after treatment is quite clear, free from dirt, soap, lime, and soapy oils; and, furthermore, it gives a good lather with soap on being used again. The same water may be treated by this method and used an indefinite number of times. The only fresh water required is that to replace the loss caused by cleaning the tanks. No great quantity, however, is requisite, since most of the contents of each tank can be pumped into the succeeding one until the sediment is reached.

In experimenting with the working model, in order to ascertain the size of the charcoal filter required for dealing with 4000 gallons a day, it was shown that the rate of flow through the filter varied directly as the height of the superimposed column of water. A charcoal filter 6 feet square was found to be adequate. This filter consists of a wooden frame 6 feet square and 18 inches high, lined with zinc. The floor, made of zinc, is perforated with holes of medium size. The latter is covered with sacking, on which a layer of powdered charcoal 4 inches thick is spread. This is covered with sacking, which is changed and washed daily.
A separate bathroom for officers, on the same principle, has now been added, and as many as 35 in one day have taken advantage of it.

The system I have described is characterised by its easy method of construction, its simplicity, and its mobility. It has now been working for sereral months, and its results have proved satisfactory in every way. I can strongly recommend this method as highly suitable where large numbers of men have to be dealt with, and more especially in those places where water is scarce.

\section{MEDICINE AND THE LAW.}

\section{The Ciase of Iieutenant Codere.}

AT the recent assizes at Winchester Lieutenant Georges Codere, of the 41st Canadian Regiment, was sentenced to death on Feb. 5th for the murder of Sergeant H. M. Ozanne, of the 9th Canadian Rifles, at Grayshott on Dec. 8th, 1915. The fact that Codere killed Ozanne was not in dispute at his trial, the defence turning upon the question whether the prisoner was, or was not, insane in a degree recognised by the law as absolving him from responsibility when he com. mitted an act which otherwise constituted a murder. characterised by brutal cruelty and by no small amount of effrontery. Mr. Justice Darling appears to have attached no great weight to the defence of insanity and to the evidence called in support of it, and the prosecution was able to lay medical evidence before the jury to rebut that put forward on the prisoner's behalf. Dr. Maurice Oraig was called, having been instructed by the Treasury to visit and examine Codere in prison, and his testimony as to nothing abnormal, such as would suggest irresponsibility, being observed by him is entitled to the greatest weight. At the same time, it will be a source of some surprise if the verdict of the jury, stated to have been arrived at in 20 minutes, does not occupy for a longer period than that the attention of the Court of Criminal Appeal and of the Home Office. In these circumstances we refrain from recapitulating. It is also undesirable to do more than to say that the prisoner was regarded as eccentric in his regiment, and that there were facts narrated as to his personal and family history as well as medical evidence of his present condition which will no doubt receive further and serious consideration.

\section{"Personal Knonledge."}

At the Central Criminal Court recently Dr. A. H. Vassie was found not guilty on an indictment charging him with the serious offence of making a false declaration for the purpose of enabling a person to obtain a passport. There can be no doubt that Dr. Vassie had not the slightest intention to evade or infringe the law, and he is entitled to be congratulated upon an acquittal which no doubt embodied the opinion of the jury to that effect. That he did in some degree act imprudently may be said to be proved by his having been compelled to submit to the ordeal of prosecution by the authorities, and his case should serve as a warning to medical men and others who may be urged, as he was, to oblige their patients or friends. Dr. Vassie was approached by an old patient, the uncle of a woman who wished to go abroad, and was asked to make the usual declaration on her behalf, to the effect that to his personal knowledge he could rouch for her being a fit and proper person to receive a passport. She was introduced to him and he questioned her in such a manner as to assure himself of her good faith. She said that she was going to Germany to nurse her mother, and there was nothing to suggest that she was not a fit and proper person to receive a passport. Nevertheless the passport came into the hands of the police when they arrested the woman under the Defence of the Realm Act in July, 1915, nearly a year after Dr. Vassie's intervention in the matter, and she was sentenced to ten years' penal servitude The judge, summing up, pointed out that the fact of the applicant being personally questioned by the accused made it impossible to say that he had no personal knowledge of her. In cross-examination for the defence 